\title{
The Architecture of 3D Administration
}

\author{
István Tózsa ${ }^{1}$ \\ ${ }^{1}$ Department of Economic Geography and Futures Studies, Corvinus University of Budapest, Hungary \\ Correspondence: István Tózsa, Department of Economic Geography and Futures Studies, Corvinus University of \\ Budapest, BCE, 9 Fővám tér, Budapest, Hungary. Tel: 36-919-5677. E-mail: istvan.tozsa@uni-corvinus.hu
}

Received: January 20, 2014 Accepted: March 25, 2014 Online Published: April 29, 2014

doi:10.5539/par.v3n1p68

URL: http://dx.doi.org/10.5539/par.v3n1p68

\begin{abstract}
The objective of this article is to introduce the main blocks in building virtual front and back offices of public administration. Virtual administration is probably kind of an ultimate or top stage of ICT platforms of e-government. First a justification is given why 3D government fits in the recent EU directives of e-government development. The relevant scholarship contains a brief description of the visualized e-government, and then a fully illustrated, step by step survey reveals the itinerary to construct virtual government which is the main result of the study. The article concludes with a discussion on the practical benefit of such a research if there is one.
\end{abstract}

Keywords: t-government, virtual reality in public administration, virtualization

\section{Introduction}

\subsection{Introduction to the e-Government Environment of Virtual Reality}

The Coordinating for Cohesion in the Public Sector of the Future (COCOPS) is a major European Union project in public administration research (Note 1). Its Working Program 8 aims to explore the futures of public administration reforms in the special highlight of the measures so far taken in the name of new public administration and the ongoing global economic crisis hitting Europe's economy severely. There are symptoms of the changes that are emerging in the new modes of governance towards demand-driven and responsive character. The COCOPS team say that structural changes have led to a growth of network governance-style arrangements and a virtualization of the public sector through the growth of e-government (Walle, 2013). The topic of this study aims at introducing the theory of the convergence of the digital interactive television and the virtual reality programs applied in the content development of e-government.

The issue of virtualization and e-government is important, because the budget-cutting strategies introduced in public administration in many countries seem to work against the priorities of responsive, inclusive and customer friendly government like it has been observed in Germany, France, Spain and Hungary where the international comparative research revealed a considerable deteriorated state of public administration services over the last five years (Walle 2013) as reflected in the public managers' perceived impact of new public management measures.

The study relates to few previous works (e.g. Jenei, 2010; Tózsa, 2012, 2013) in the area as the topic concerns future development of public sector service content.

The objectives of the study include

- outlining the scope of content development for digital interactive television and virtual reality applications in a customer friendly front office service and a cost effective back office operation;

- the tasks that have to be observed when doing research and pilot applications in these ICT platforms;

- the convergence of the communication tools in mobile, television and virtual reality Internet devices, similar to the one we have witnessed in the case of smart phones (i.e. the convergence of cell phones and the Internet).

Therefore it is rather a hypothetical study of considerations of the futures of public services, where the practical content development issues are perceived in pilot working models and not in any actual front or back office operations. Evaluation and surveying the practical applications are tomorrow's issues. 


\subsection{Importance of Virtual Reality in Administration}

To underline the importance of the topic two quotations can be mentioned from Friedrich August von Hayek professor. The first one goes 'governance is the art of causing the least possible damage to society' and it has been the major philosophical initiative of the introduction of e-government and all public administration reforms that have tried so far to improve government services. According to the other 'the more the state plans, the more difficult planning becomes for the individual.' In electronic-government the workflows have to be digitized what requires planning and automation. The lack of personal contact between the customer and the customer representative is often mentioned as one of the main reasons blocking the widespread application of e-government. When virtual reality is going to be introduced in e-government, this problem, however, seems to be solved as it will be seen in this article. Also, at present, if the avatars of real bio-physical form are not taken into consideration, there is no further stage of ICT development available in theory for government administration purposes than the Internet-based convergence of interactive digital television and smart phones.

\subsection{Relevant Scholarship on e-Government Modernization}

Interactive Digital Television (iDTV) has emerged as one possible platform, since it brings an interactive capacity to a medium that is both familiar and easy to use. While we now have a significant evidence base of provider and user experiences, the relative immaturity of the technology and the nature of the iDTV initiatives themselves have prevented a full investigation of electronic public services via iDTV (Smith \& Webster, 2006). This may also be due to the interest and market policy of the large multinational broadcasting companies who have to protect their IpTV services on the one hand and have to prevent the market distribution of the decoders with Internet modems needed for interactive DTV on the other. The selling of more advanced DTV decoders ensuring interoperability will have to be due, when there is a stronger market demand for that in the information societies all over Europe I suppose, based on the informal information received from one of those companies. Until then the international EuroITV Conferences are to strengthen the future social demand, with introducing research project reports on the application of iDTV mainly in local community building processes.

The best way to contribute to electronic and mobile government is by creating a public administration network in virtual communities. This could be a proper definition of Virtual Public Administration (VPA) as pointed out by Kapogiannis et al (2008). They came to the conclusion that where the sense of time is presented in terms of project management implementation in virtual and real terms, procedures in virtual reality could be more effective in terms of time, management of risk and service levels. Their perception may serve as the basic platform of iDTV and virtual reality convergence as it was among the first ones to summarize the benefits of virtual reality - in the public sector and in virtual communities. That is what the iDTV projects aim at, too: virtual communities, simplicity to use, interoperability, less time needed and risk in management or administration.

However, the public administration application of iDTV was a rather unique idea in the middle 2000s (Tózsa 2006) and was still in 2010, when it was first introduced on the program of EuroITV in Tampere Finland as an independent panel discussion (Jenei, 2010).

\subsection{Application Design}

In late 2011 the American Utherverse's Hungarian distributor (Virtual Planet's) offered the Faculty of Pubic Administration a co-operation in e-government development, as they were planning to build a virtual city with entertainment facilities, banks, shops and a municipality. Using the so far collected experiences in constructing administration workflow for mobile handsets and television, the Budaörs Municipality was chosen as a pilot environment for virtual 3D administration. Budaörs is a small Hungarian town west of Budapest, which is the capital city. It is situated in a gateway position of the capital and its local government office was used for testing mobile and television government experiences by the University earlier. After creating the office environment a successful press conference took place in the summer of 2012 where the operation of the pilot was introduced displaying a real time conversation between the avatars of a customer and a customer representative in front of the professional press and an audience of local government employees, professionals and academic representatives from the University. The results and the output of the pilot are published in a Video (accessible in Hungarian language at Tózsa, Illés, \& Gelencsér, 2012) and in a study in English (Tózsa, 2013). In the following a somewhat more elaborated approach is published regarding the building of a system to be applied in municipal front and back office processes. 


\section{Architecture}

Figure 1 shows the proposed structure of building 3D government with the front office functions on the left in grey and the back office ones on the right in black. The arrows show the sequence of establishing the functions. The major ones are the creation of the office environment and the interactive function of the dialogues.

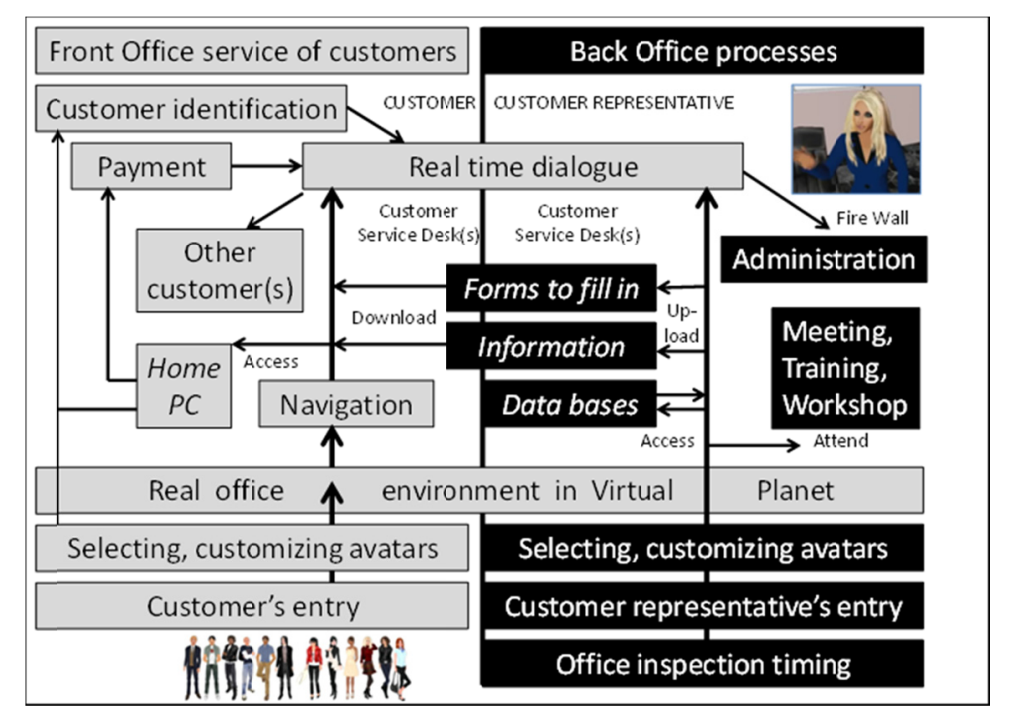

Figure 1. A possible design to build a 3D virtual reality local government

\subsection{Identification of the Subsections of the 3D Government Architecture}

Parts of the 3D government structure include entry into the virtual government system, selecting and customizing the avatars and their interactive and functions, entering the office environment, navigating, up- and downloading information, having access to remote and government databases and the ones on the customers home PC, interactivity among the customers and the customer representatives, downloading forms to fill in and returning them for further administration, identification of the customers and receiving their payments. When introducing the panels from which the architecture of the 3D government is to be built up it is unavoidable to employ many figures and slides from the program to visualize the construction of virtual administration. In reading the following, basically Figure 1 has to be observed throughout.

\subsection{Characteristics of the Elements}

Office inspection timing An office that is applying 3D administration has to provide working hours in the virtual environment possibly encompassing the evening hours and weekends, too. Customer representatives of course can stay home and can be given extra free time and flexible working hours for taking weekend or evening inspections. According to the timing, clerks, i.e. their avatars on duty have to be present permanently in the 3D government program to help customers. This function provides a basic requirement of e-government, to be available for the customers virtually at any time from any place.

Customers' and customer representatives' entry into the program The program of $3 \mathrm{D}$ government, once it is developed and issued has to be accessible for anyone free of charge as it serves the same way as entering a real municipal or government office. The downloading and running of the program requires $2 \times 1.8 \mathrm{GHz} \mathrm{CPU}, 2 \mathrm{~GB}$ $\mathrm{RAM}, 128 \mathrm{Mb}$ VGA, $600 \mathrm{Mb}$ free hard discs, and a recommended Internet bandwidth of $2.5 \mathrm{Mbit} / \mathrm{sec}$. These are parameters offered by most operating systems and available online PCs. The technical requirements show there is no special technological development demand for the application of 3D or virtual government in most of the developed countries. The launch of the virtual government is a question of (local) government decision and needs only customizing knowledge, some HR organizational steps to take by the office, and the building of the virtual environment of the (local) government office.

Selecting, customizing avatars by both customers and customer representatives are similar. The stock to choose avatars from has to be limited to gender, age, and personal style not permitting extraordinary or fantasy characters in order to upkeep the solemnity of administration and local authorities. Figure 2 and 3 show an example of the stock from which avatars can be selected. It is a question of the elaboration degree of the program whether real 
photographs of the customer (or the clerk) are accepted in customizing the figure of the avatar; see it also in Figure 2. This architectural step is the one where during pilot applications the customers and clerks can train themselves in customizing the navigation and interactions with their avatars. There is a panel explaining and teaching the users how to operate in the virtual office, see Figure 4. They can navigate their avatars either with clicks of the mouse or by using the keyboard or a touch screen as it is explained in the right bottom corner of the panel. They can set the forms of their dialogues (text or voice) as it is shown in the left bottom corner of the panel. The dimensions (display, number of avatars and the scenes of the office environment) can be set as seen in the right upper corner. The identification and the display (transparency) of the avatars to be seen by the other ones having entered the virtual office, or by just the customer representative, can be set as seen in the left upper corner of the panel. If the owners of the program want to make it a bit more sophisticated, the basic information panel for navigation and interactivity can be adjusted with the selected avatars 'in person.' See it in the picture of Figure 5.

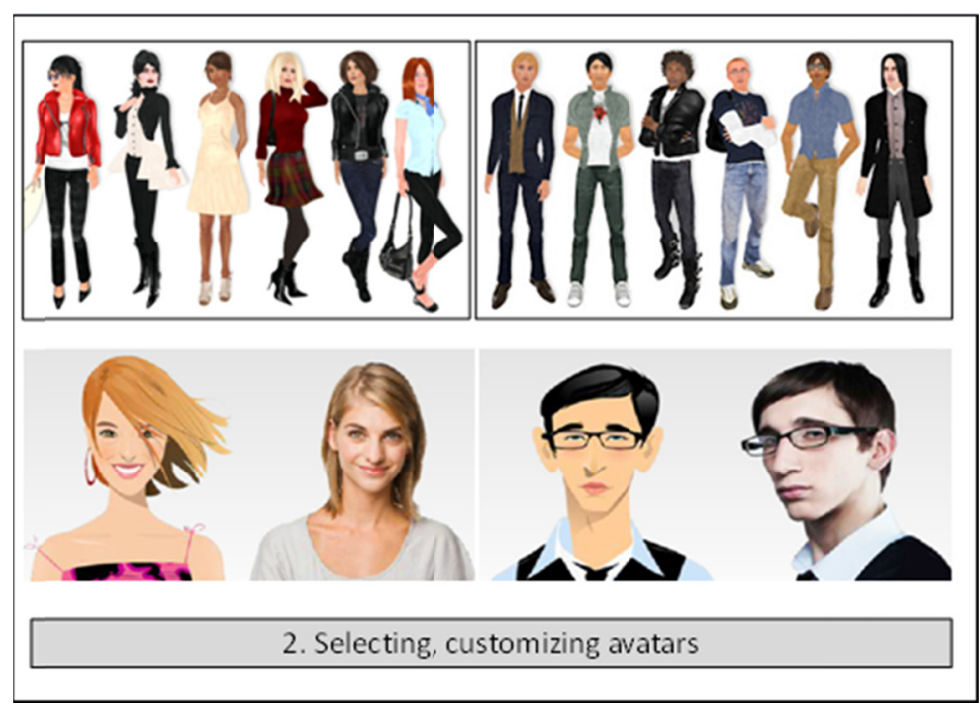

Figure 2. A possible choice of consolidated avatar figures which can be further customized with own photo profiles (Sources: http:// New Starter Avatars, My Web Face)

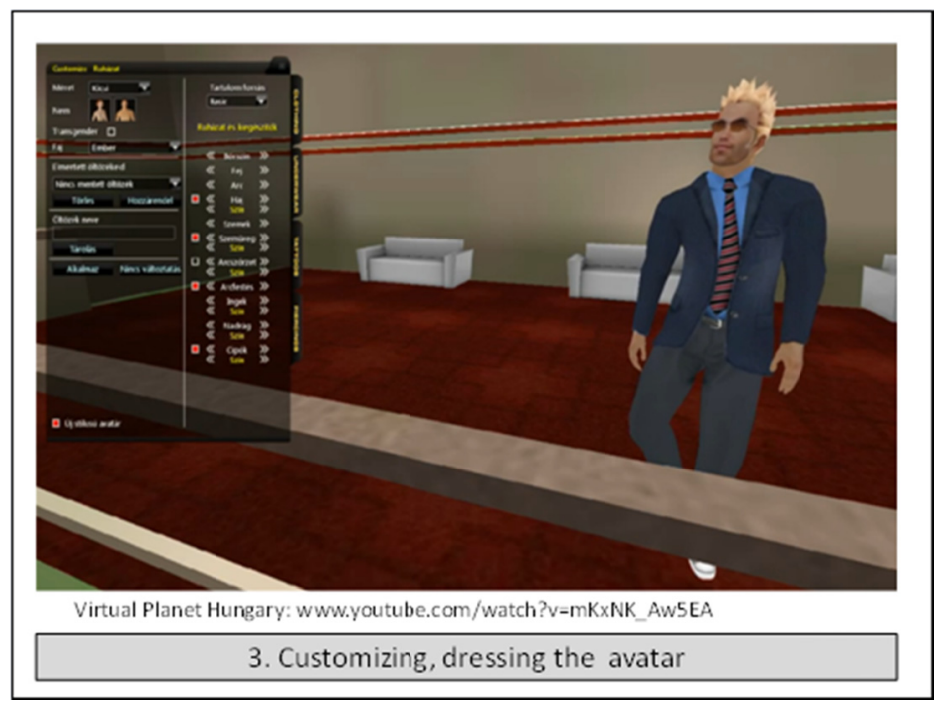

Figure 3. Having chosen an avatar, the customer enters the virtual environment

(Source: http:// Virtual Planet Hungary) 


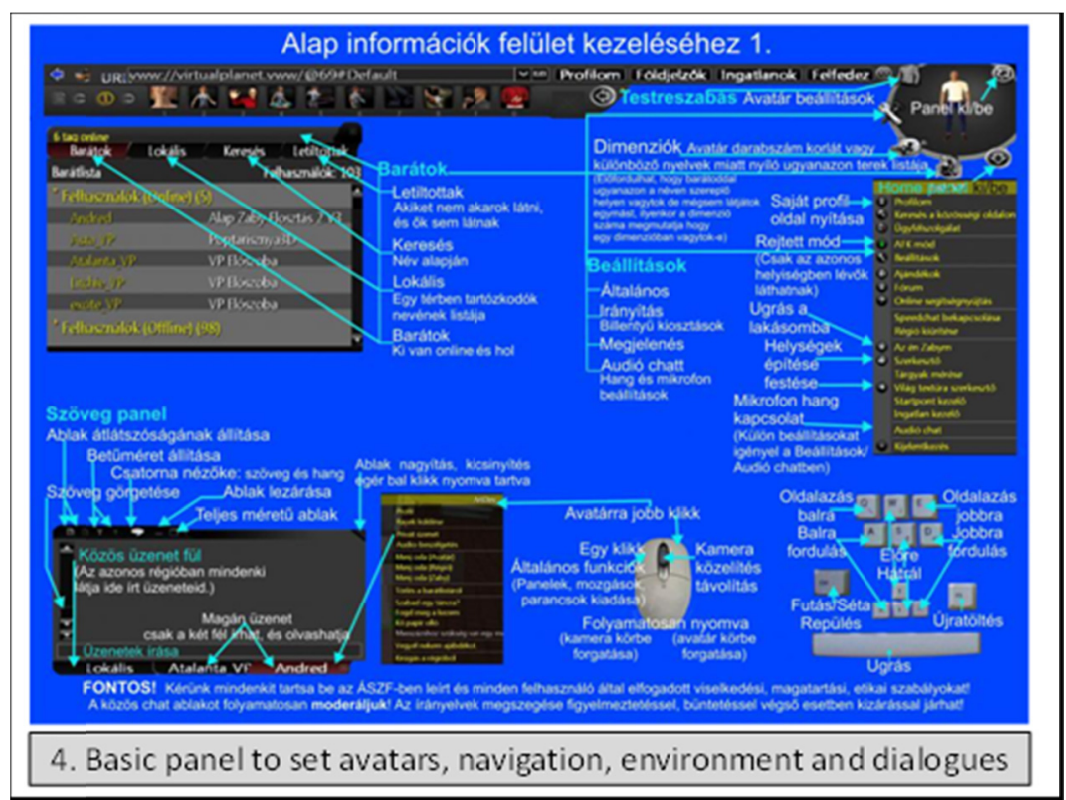

Figure 4. Basic information how to set the navigation tools, interactivity and the virtual environment as elaborated by Virtual Planet Hungary Ltd (2013)

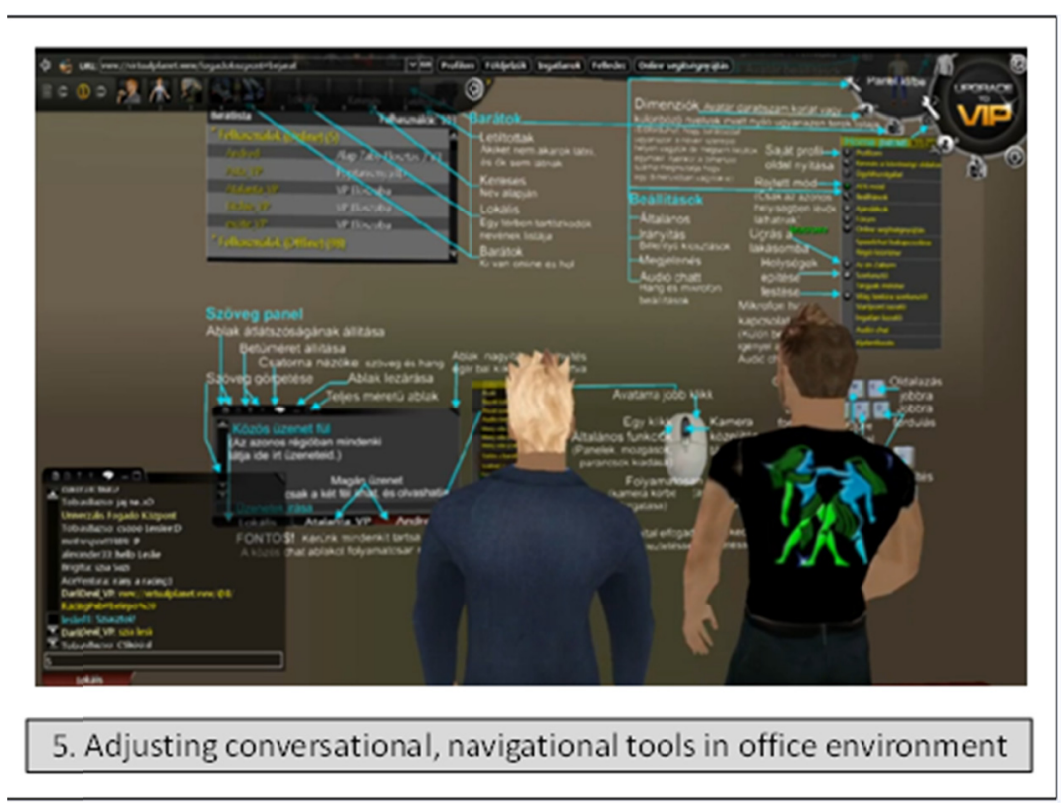

Figure 5. Avatar setting possibility within the 3D environment as designed by Virtual Planet Hungary (2013)

Real office environment in Virtual Planet When applying 3D government at a municipality it is recommended to build an office environment which is very much like the real one there. So customers entering the office can feel as if they were at their hometown office. During the program implementation the developers take photos of the building from the outside and from inside regarding all front office services of the departments where they decide $3 \mathrm{D}$ administration is going to be introduced. On the basis of these photos the $3 \mathrm{D}$ office environment can be constructed. See Figure 6. As for back office, it is advisable to include the 3D environment of the meeting room, or where the post graduate trainings for clerks usually take place, too. 


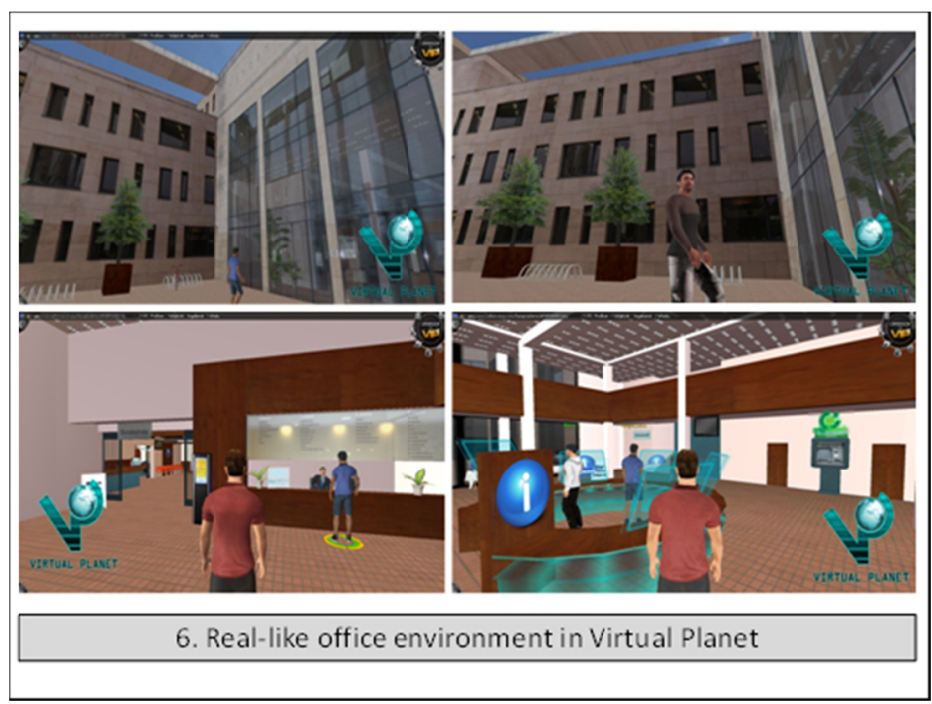

Figure 6. A local government in virtual reality resembling the real one

(Source of pictures: Tózsa, Illés, \& Gelencsér, 2012)

Navigation As it was seen in Figure 4 with the movement of the mouse or the keys it is possible to move forward and turn around with both the avatars and the camera perspectives (right or left clicks), thus we either move around with the avatars or move the environment around them. Minor gestures can be expressed by our avatars like e.g. expressing impatience (looking left and right) if our avatar has to wait, or confusion (scratching the head) if we do not know where to find a department or a customers' representative. See Figure 7.

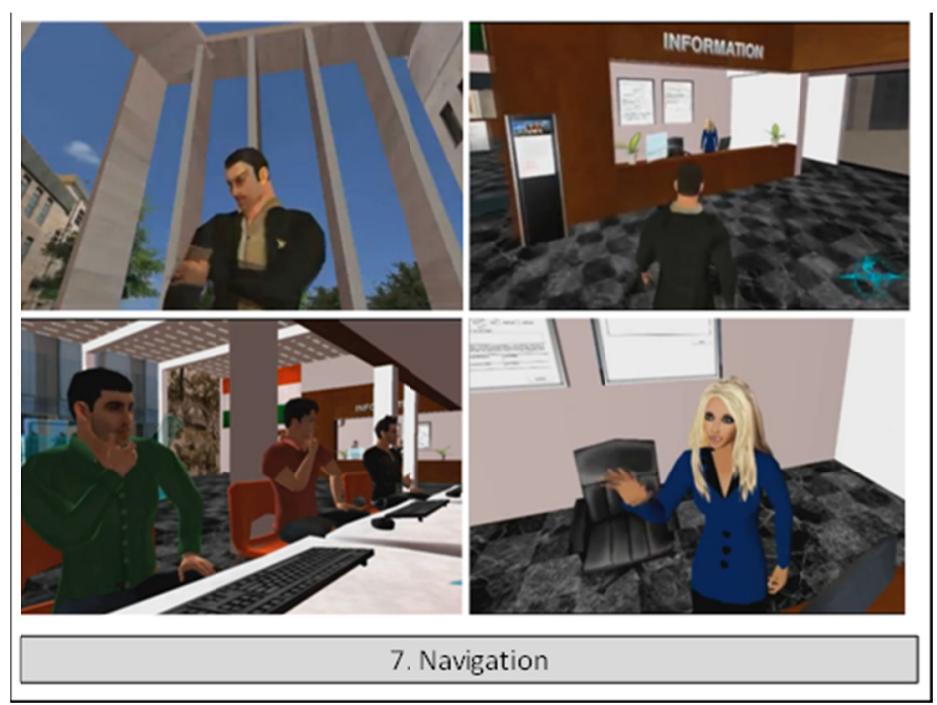

Figure 7. In navigating the avatar, either the figure or its environment can be moved around

(Source of pictures: Tózsa, Illés, \& Gelencsér, 2012)

Information is a function available by both the customer and the customer representative avatars. In the back office environment new items of information can be uploaded and in the front office environment the customers' avatars can read and download the actual or needed information that can regard either actual local news or instructions e.g. how to apply for certain documents. See Figure 8. 


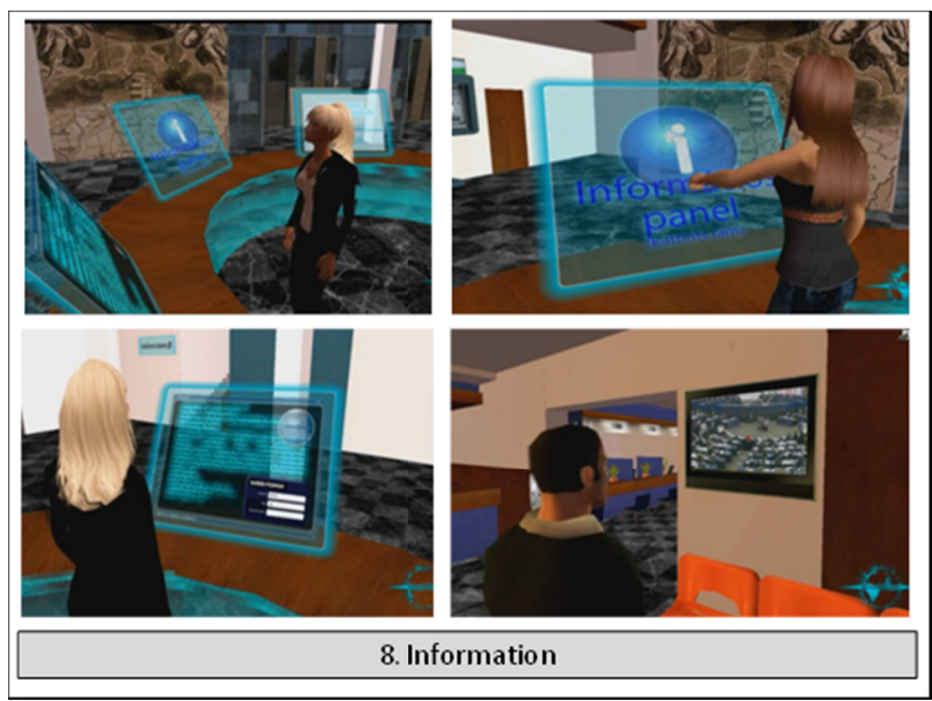

Figure 8. The same actual information of local or workflow importance can be read as in the real office

(Source of pictures: Tózsa, Illés, \& Gelencsér, 2012)

Forms to fill in are functions available again, like information, both from front and back office environments. The clerks can upload the effective and valid forms e.g. applications, data sheets that are needed in different workflows and the customers' avatars can download and fill them in practically with the immediate help of the avatar of the clerk. The downloaded, filled in and returned forms are parts of the administration function. See Figure 9.

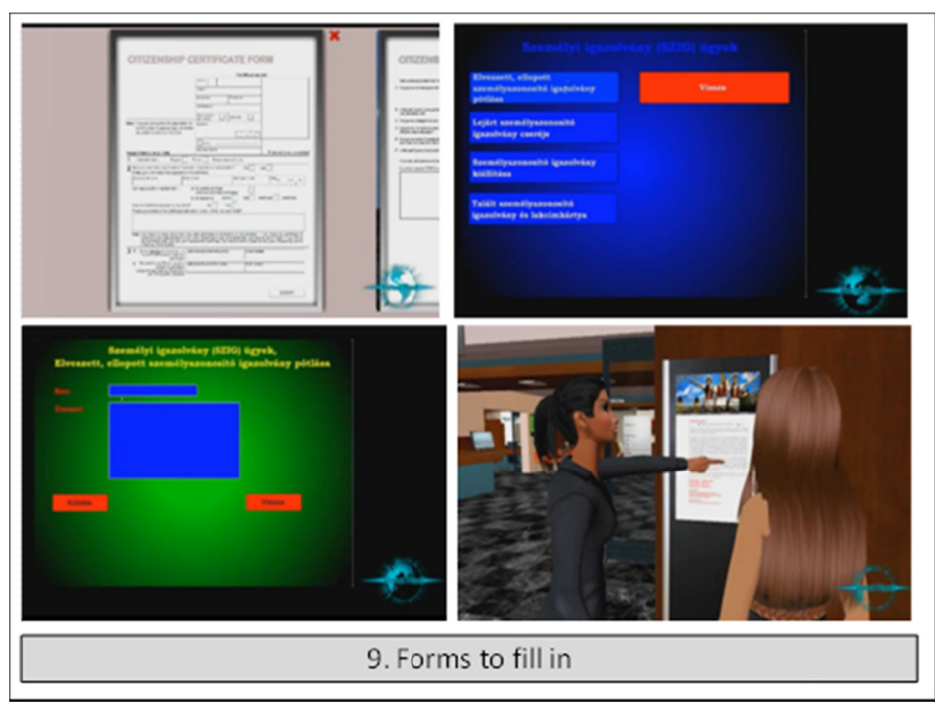

Figure 9. The downloadable forms to fill in and return with the assistance of the clerk accelerate workflow

(Source of pictures: Tózsa, Illés, \& Gelencsér, 2012)

Data bases represent the back office access either to the data bases of the local government or to the central national data bases like land registry, personal data of citizens stored at the Ministry of the Interior and needed for issuing passports, driving licenses, death and birth certificates etc. It is the same official access every local authority has.

Meeting, training, workshop are back office functions in which the avatars of the clerks and civil officers can take part in real time meetings or post graduate trainings from home or elsewhere. It is also a time and travel cost saving benefit of the 3D government. See Figure 10. 


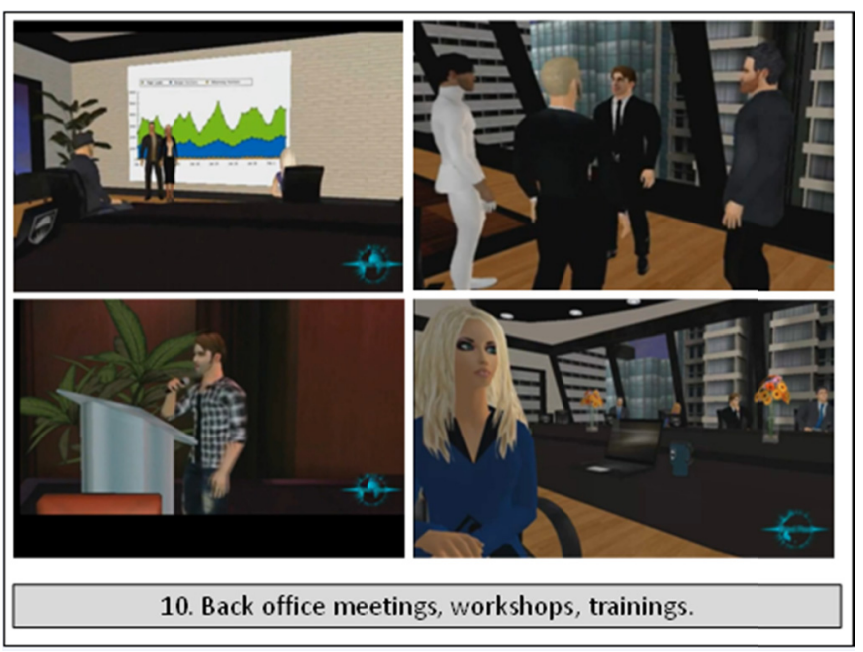

Figure 10. Back office environment provides cost and time saving functions

(Source of pictures: Tózsa, Illés, \& Gelencsér, 2012)

Home PC The customers have access to the data stored on their own computers to be able to obtain personal data, $\mathrm{CV}$ or photos from there and to convey them where they are needed in the workflow of administration.

Other customers When an avatar enters the virtual municipality, all the other avatars having already entered the same program can be seen simultaneously. If there are several avatars already intending to do administration at a certain CRM desk, they can queue up just like in reality, though the time saving benefit of the virtual office is evident for the real customer at home. They can not only see one another, but can initiate a conversation depending on the setting performed at the stage entitled 'Selecting, customizing avatars.' If the dialogue with other customers' avatars is permitted in the setting they can have one either voiced or in text again depending on the setting. They can see one another's abbreviated names only and not their identities of course. See Figure 11.
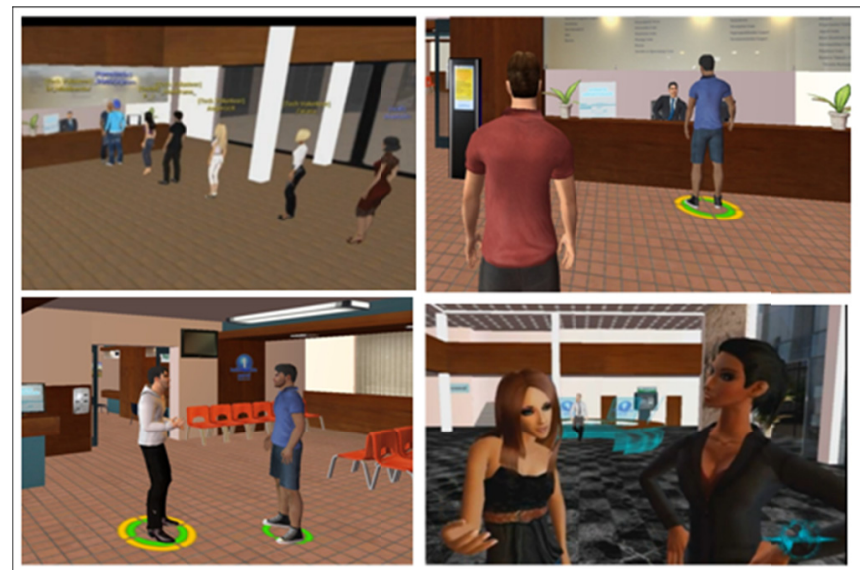

11. Other customers

Figure 11. Entering into dialogues with other avatars in the office provides local society building function

(Source of pictures: Tózsa, Illés, \& Gelencsér, 2012)

Customer identification is the most important stage and the weakest link in 3D government as it has been in the 'traditional' e-government, too. As in case of all e-government and e-signature authentication the customers having applied for a registration code have to go to the office in person to identify themselves. At places where the administration is modern enough to reduce the waiting time citizens tend to choose administration in person instead of opening an e-government access for themselves. Besides, due to the relatively few e-customers most 
office clerks have little or no experience in receiving e-government customers. Therefore the transformation sophistication level of e-government is reached only in the cases of the EU's Common List of Basic Public Services for business companies in tax return or other services that have been made compulsory by law. However, the 'traditional' electronic identification can be part of the 3D government, but if it is getting popular and widely used among customers can be questioned. In future the greatest challenge of e-government or 3D government applications is to include video cameras or digital biometric tools to solve identification easier and quicker than it can be done today. In the Budaörs project (Tózsa, Illés, Gelencsér 2012) Customer identification and Payment was not elaborated in the system, which thus allows the users only navigation in the $3 \mathrm{D}$ office environment, dialogues, giving and asking for information, access to forms to accelerate administration, but in the end of the workflow customers have to go to the office in person to identify themselves and obtain the required certificate or authorized document.

Payment has the same problem as the Customer identification panel. Of course, once the customers have e-banking access, its messages can be joined to Virtual Planet's office environment and banking notifications can authenticate the payment of different fees.

Real time dialogues stand for the central and most attractive function of 3D government. It is the dialogue between the customer and the customer representative. The result of this dialogue can not only provide information useful for the customer, but can accelerate administration as well. The avatar of the clerk can help the avatar of the customer to download forms and fill them in properly, then sending them back to the office to initiate workflows. If the identification of the customer is solved (he or she has already obtained registered code) the whole procedure can be accomplished without the customer's personal visit to the real office, just like in the case of a 'traditional' e-government process on the transformation stage. See Figure 12.

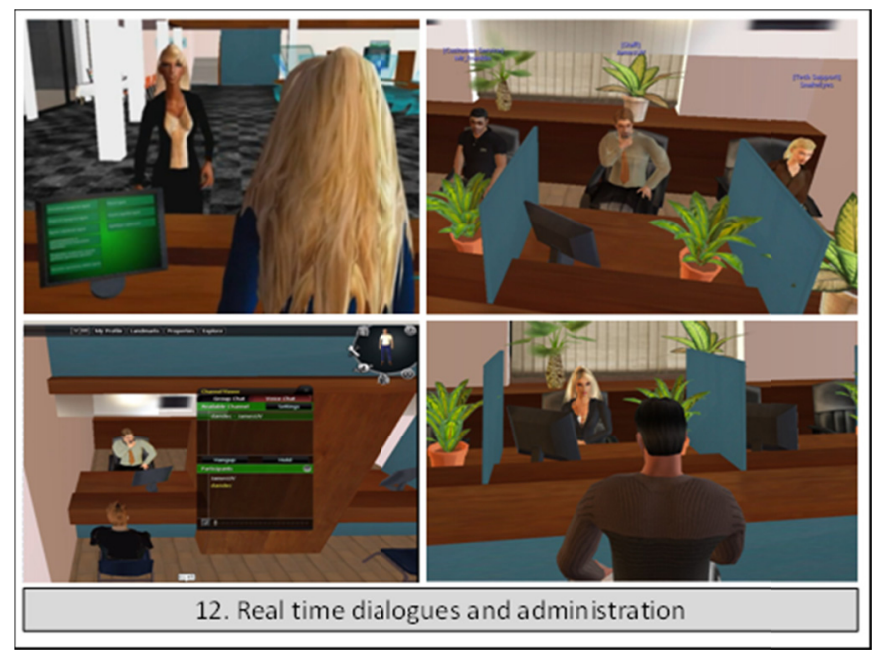

Figure 12. Not only can 3D workflow accelerate administration, but has the potential to create e-government on the transformation and targetization levels (Source of pictures: Tózsa, Illés, \& Gelencsér, 2012)

Administration The Virtual Planet program can be linked to the 'traditional' administration of the back office via a firewall, so all the data and forms provided by the customer and the required data downloaded from the national data bases can be joined to the proper back office workflows as usual.

\section{Results}

During 2012-2013 a pilot program created a 3D office environment for Budaörs municipality in Hungary which resulted in a working model of virtual administration including most of the functions shown in Figure 1. Due to the lack of a major state project and any financial support, customer identification, payment transfer possibility and the accesses to external data bases (private computers, office servers, national registries and citizens' data bases) were not implied at all in the pilot. However, the office environment exists in which the chosen avatars can move around and enter into real time dialogues with all other avatars having simultaneously entered the system, including that of the clerks. On the basis of this pilot any municipality or local government institution can easily adapt the 3D functions. 
Figure 13 shows the process how the basic ICT tools (telephone, television and Internet) converge and develop into the 3D reality platform of which a higher degree of development is not known so far. As long as the bio-sensor equipped avatars are not going to appear in the physical environment, but that is another story. In the very beginning of the 21 st century cell phones were getting involved in the administration processes in the form of sending SMS thus accelerating workflows. The Internet protocol TV and the digital video broadcast for the cable can have public service and administration content, but their interactivity just like in the case of the radio channels can manifest itself in the form of cell phone calls integrated into the programs on the one hand. Digital interactive $\mathrm{TV}$ on the other hand has an important potential in generating interoperability aiming at the digital illiterate and the net-less social layers in the first place. Smart-phones are used as mobile Internet access tools.

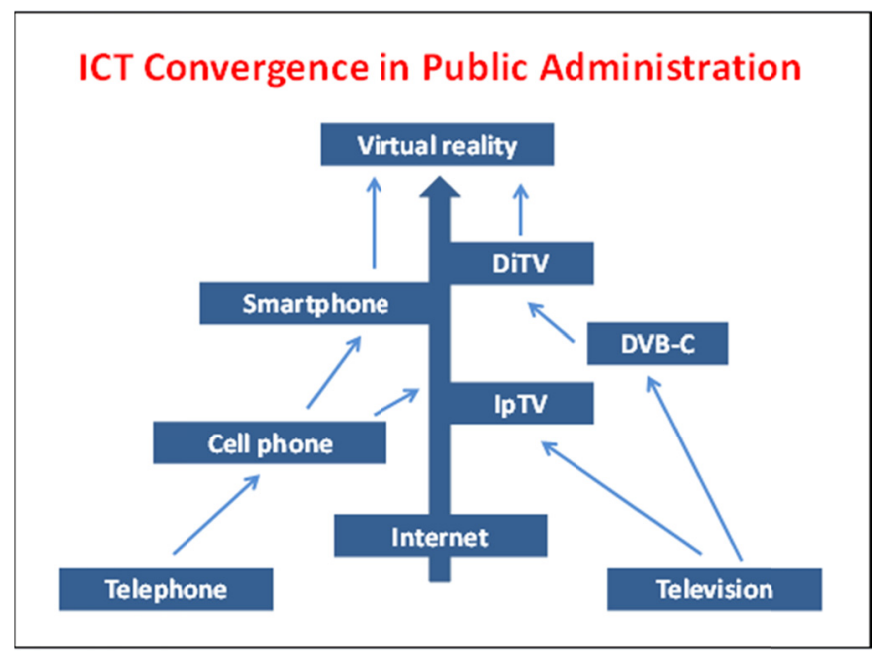

Figure 13. Evolution of 3D administration as reflected in its ICT platforms

\section{Discussion}

The results of the 3D pilot application in public administrative environment fit in the future expectations of the e-government development designed in the e-Europe plans having been recently manifested in the COCOPS program. The theoretical and practical consequence of the results is a kind of itinerary of how to build a 3D office environment for public administration purposes.

What remains unsolved is the piloting in customers' identification, banking and accessing to external data bases and it is explained by the lack of any financial means in working it out. That is the reason why the 3D proposal was not supported financially and the only resources put into the pilot were that of the Virtual Planet Hungary Ltd and of some enthusiastic administrators at the municipality of a Hungarian town. The question is why Government does not see t-government and 3D administration useful tools in developing e-government?

As the author sees, all Eastern-Central European EU governments have to declare, officially that they support the development of e-government as it is a strong recommendation and expectation of the EU. Though if the objectives of public administration development projects are observed in most cases there are technical developments, like renewing and changing the computers in the offices, creating databases, starting post graduate training for clerks, improving the legal rulings, etc. The truth which is not encouraged to display is that there is no motivation to apply and develop e-government contents. Motivation, apart from the EU expectations, is missing on the side of the central governments, on the side of the local governments and last, but not least on the side of the citizens all over in Eastern-Central Europe. A legal act to make e-government compulsory can improve the situation, but no government is taking the risk of initiating such an act for citizens, only for company taxation and business administration. The majority of local governments and local citizens for whom e-government, including t-government and 3D administration, could be the largest benefit, cannot afford to invest in establishing it. They have enough problems regarding unemployment, social care, and hardly enough energy is left to establish and accept development and new ICT platforms of administration. This, however, would lead us far. 


\section{Future Challenges}

'The futures of an agency's work now rests in new and evolving technologies that support real-time, dynamic interactions.' This is exactly where the building of the 3D virtual administration fits in. The new 'applications demand dynamic technologies involving data access, database management, authentication, and security of a very different nature from the old Web. The dynamic Web makes closer connections between an agency's internal systems and the outside world, presenting new risks and demanding new tools and techniques for managing them.' (Dawes 2002) This quotation though more than 10 years old, still can be seen on the web page of the Centre for Technology in Government (University of Albany) serving like a justification of the shift from the static Web to a dynamic and interactive Web.

One thing is sure, navigare necesse est, as Pompeius Magnus had said, scientific survey, academic research and university education of the new horizons must not stop either because of financial difficulties or the temporary lack of social demand. In a step by step approach to the perfect and virtual, visualized e-government it is wise to hold with the Japanese proverb that goes like 'vision without action is daydream, but action without vision is nightmare.'

\section{Acknowledgements}

Virtual Planet Hungary Ltd prepared the software application to an actual Hungarian municipality (Budaörs) where the head of the document office, István Benkő and his colleagues provided help and co-operated in ensuring the office environment in 3D. Proof reading of this article was performed by Virtual Planet Co.

\section{References}

COCOPS. Retrieved December 22, 2013, from http://www.cocops.eu

Dawes, S. (2002). The Future of e-Government. Centre for Technology in Government, University at Albany, NY, USA. Retrieved January 17, 2014, from http://www.ctg.albany.edu/publications/reports/future_of_eg ov? chapter $=2$

Hayek, F. A. (1944). The Road to Serfdom (p. 266). U.K.: Routledge Press.

Jenei, Á. (2010). T-Government; Interactive TV in Public Administration. Edited by I. Tózsa. Panel Report during the $8^{\text {th }}$ EuroITV Conference held in Tampere, Finland, $9^{\text {th }}-11^{\text {th }}$ June 2010 . Retrieved from http://www.etourandgeo.com/admin/TGOVKezirat.pdf

Kapogiannis, G., Kreps, D. G., \& Polychronakis, Y. E. (2008). Virtual Public Administration Procedures through Project Management. Paper presented at the PM-04: 4th SCPM \& 1st IPMA/MedNet Project Management Conference in the Mediterranean, 29-31 May 2008, Chios Island, Greece (http://2008.pmgreece.gr)

My Web Face. Retrieved December 20, 2013, from http://download.mywebface.com

New Starter Avatars SL1. Retrieved December 20, 2013, from http://irez.me/wp-content/uploads/2012/08/ newstarteravatarss122.jpg

Smith, C., \& Webster, W. (2006). Interactive digital television and electronic public services: Emergent issues. ECIS 2006 Proceedings. Paper 121. Retrieved from http://aisel.aisnet.org/ecis2006/121

Tózsa, I. (2012). T-Government Chinese-European Cooperation for a Long-term Sustainability. Corvinus University of Budapest. Retrieved from http://korny.uni-corvinus.hu/cneucoop_fullpapers/s5/istvantozsa.pdf

Tózsa, I. (2013). Virtual Reality and Public Administration. Transylvanian Review of Administrative Sciences, 38. E/2013, 202-2012. Retrieved from http://www.rtsa.ro/en/files/TRAS-38E-2012-11TOZSA.pdf

Tózsa, I., \& Budai, B. B. (2006). M-Government, T-Government - Latest Technological Trends in Public Administration (p. 138). E-Government Foundation and the Corvinus University of Budapest.

Tózsa, I., Illés, Zs., \& Gelencsér, Á. et al. (2012). Budaörs Project (Video in Hungarian language). Retrieved from http://indavideo.hu/video/Budaors_Project

Virtual Planet Hungary. Retrieved December 20, 2013, from www.youtube.com/watch?v=mKxNK_Aw5EA

Walle, S. V. (2013). Coordinating the Public Sector of the Future; COCOPS at a Glance. Department of Public Administration, Erasmus University, Rotterdam. 


\section{Note}

Note 1. COCOPS - Coordinating for Cohesion in the Public Sector of the Future is a public management research consortium consisting of 11 universities in 10 countries. With a budget of nearly 2.7 million $€$ from the European Commission's FP7, this is to become one of the largest comparative public management research projects in Europe. The project started on 1 Jan 2011 and is running for 3.5 years. It is coordinated by Erasmus University Rotterdam (http://www.cocops.eu).

\section{Copyrights}

Copyright for this article is retained by the author(s), with first publication rights granted to the journal.

This is an open-access article distributed under the terms and conditions of the Creative Commons Attribution license (http://creativecommons.org/licenses/by/3.0/). 